\title{
Trânsito de saberes e campo representacional na visão dos profissionais da Saúde da Família e do Programa de Educação pelo Trabalho e para a Saúde
}

\author{
Knowledge in transit and representational field in the professional view of the Family Health and Work and \\ Health Education Program
}
Transferencia de conocimientos y campo de representación en la visión de los profesionales de Salud de la Familia y del Programa de Educación por el Trabajo y para la Salud

A Estratégia de Saúde da Família (ESF) emerge como uma possibilidade de reestruturação dos serviços e de novas práticas de intervenção na atenção à saúde, requerendo profissionais capacitados. Para tal, foi instituído o Programa de Educação pelo Trabalho e para a Saúde (PETSaúde), visando integrar ações de ensino-serviço, com foco na atenção básica. O objetivo deste trabalho foi apreender a representação social do enfermeiro, médico e odontólogo, preceptores do PET-Saúde, do município de Natal-RN, sobre a Estratégia de Saúde da Família, enquanto campo de prática dos mesmos. Trata-se de estudo descritivo-exploratório, de abordagem qualitativa, realizado em sete unidades de Saúde da Família (USF) que integram o PET-Saúde Natal (RN). A amostra incluiu cinco enfermeiros, cinco médicos e cinco odontólogos. Os dados foram coletados por meio de desenho-estória com tema, entrevista individual semiestruturada e diário de campo. A análise e interpretação dos desenhos deram-se pela significação dada ao recurso gráfico a partir do título e das palavraschave atribuídas pelos sujeitos, tendo a ESF como termo indutor. As estórias e entrevistas transcritas e digitadas foram submetidas à leitura/ escuta flutuante do material e à análise léxica do ALCESTE. O material discursivo foi analisado à luz da Teoria das Representações Sociais. O estudo foi aprovado pelo Comitê de Ética em Pesquisa da UFRN (parecer 019/2010). A maioria dos profissionais eram do sexo feminino, com idade entre 46 e 52 anos, casados, renda mínima de seis salários, tempo de formado entre 22 a 29 anos, e de trabalho na ESF entre dois a 11 anos. A partir do ALCESTE, foram eleitas cinco categorias: ESF: relações e território; formação e desenho do vínculo; processos de trabalho na ESF; articulação ensino-serviço; e atenção à saúde e prevenção de doenças. A construção do campo representacional seguiu a lógica dos núcleos estruturantes existentes nas categorias. Conclui-se que a ESF é um ambiente com potencialidades, como a relação "muito sujeito-sujeito" e o vínculo estabelecido entre profissional-comunidade, mas apresenta algumas fragilidades, tais como precárias condições de trabalho, falta de participação popular e apoio da gestão, além de dificuldades na realização do trabalho em equipe. É imprescindível a articulação ensino-serviço com vistas à formação de um novo profissional de saúde apto para o trabalho na ESF. A formação do campo representacional encontrou uma diversidade de núcleos estruturantes, ou pensamentos em formação, acerca da ESF, devido a maior ênfase dada ao aqui-e-agora da interação entre os profissionais de saúde, a ESF, a comunidade e o PET-Saúde, ressaltando-se que tais propostas são conceitos recentes no contexto da saúde e, portanto, não totalmente concretizados no imaginário social.

Raionara Cristina de Araújo Santos. Departamento de Enfermagem. raionara_cristina@yahoo.com.br

Palavras-chave: Atenção primária à saúde. Saúde da família. Recursos humanos em saúde. Educação em saúde. Pesquisa metodológica em enfermagem.

Keywords: Primary health care. Family health. Health manpower. Health education. Methodology research in nursing.

Palabras clave: Atención primaria de salud. Salud de la familia. Recursos humanos en salud. Educación en salud. Investigación metodológica en enfermería.

Texto completo disponível em: http://pgenfufrn.files. wordpress.com/2011/04/dissertac3a7ao-raionara.pdf 